\author{
LA PRESA DE DECISIONS MORALS. \\ DIÀLEGS I CONTRIBUCIONS ENTRE \\ KOHLBERG, MEAD I HABERMAS \\ LA TOMA DE DECISIONES MORALES. \\ DIÁLOGOS Y CONTRIBUCIONES ENTRE \\ KOHLBERG, MEAD Y HABERMAS \\ THE MORAL DECISION MAKING. \\ DIALOGUIS AND CONTRIBUTIONS BETWEEN \\ KOHLBERG, MEAD AND HABERMAS
}

\title{
Mercedes Oraisón*
}

DOI: 10.7203/anuari.psicologia.18.2.39

\begin{abstract}
Resum
L'article aplega reflexions i conceptualitzacions sobre el raonament moral i la presa de decisions morals de Lawrence Kohlberg, Georg Herbert Mead i Jürgen Habermas. Entre aquests trobem interessants plantejaments on es posen en diàleg la Psicologia i la Filosofia per elucidar de manera més clara i precisa la conformació de la moralitat.

Entre les línies d'articulació o punts de convergència advertits en el pensament d'aquests tres autors i desenvolupats en l'article, es destaca la noció d'adopció de rols formulada per Mead,que Kohlberg incorpora a la seua teoria del desenvolupament moral com una operació de justícia i procediment d'universalització i que Habermas assimila a la seua proposta del discurs pràctic. Les interpretacions construïdes pels autors entorn d'aquest procés, que es rescaten ací, plantegen interessants implicacions per a esclarir la presa de decisions morals.
\end{abstract}

* Facultad de Humanidades / Centro de Estudios Sociales, Universidad Nacional del Nordeste. 3500 Chaco, Argentina. Correspondència: <mercedesoraison@hotmail.com>. 
L'aprenentatge ètic, de la mateixa manera que qualsevol altre aprenentatge, suposa una transformació en la manera d'interpretar i reaccionar al que succeeix al món, en la que cal incidir en els processos psicològics superiors $\mathrm{i}$ en la motivació, des de la sensibilitat i la interioritat, per afavorir la presa de consciència de les consequiències de les accions.

Paraules clau: raonament moral, perspectiva social, presa de decisions morals, relació Psicologia - Filosofia.

\title{
Resumen
}

El artículo reúne reflexiones y conceptualizaciones en torno al razonamiento moral y la toma de decisiones morales de Lawrence Kohlberg, Georg Herbert Mead y Jürgen Habermas. Entre ellos encontramos interesantes planteamientos en los que seestablece un diálogo entre la Psicología y la Filosofía para elucidar de manera más clara y precisa la conformación de la moralidad. Entre las líneas de articulación o puntos de convergencia advertidos en el pensamiento de estos tres autores y desarrollados en el artículo se destaca la noción de adopción de roles formulada por Mead, que Kohlberg incorpora a su teoría del desarrollo moral como una operación de justicia y procedimiento de universalización y que Habermas asimila a su propuesta del discurso práctico. Las interpretaciones construidas por los autores en torno a tal proceso, que se rescatan aquí, plantean interesantes implicaciones para el esclarecimiento de la toma de decisiones morales.

Palabras clave: razonamiento moral, perspectiva social, toma de decisiones morales, relación Psicología - Filosofía.

\begin{abstract}
The article brings together some reflections and conceptualizations around moral reasoning and moral decision making from Lawrence Kohlberg, Georg Herbert Mead and Jürgen Habermas. Between them we find out interesting approaches that put in dialogue Psychology and Philosophy in order to get a clearer and complete elucidation of moral construction.

Between lines that connects the thought of these author we focus on the notion of role taking proposed by Mead and incorporated as a part of moral development theory by Kohlberg, and as a main procedure of foundation and verification in the practical discourse of Habermas. Interpretations constructed by the author about that process, which has been rescued here, raises interesting implications to clarify moral decision making.
\end{abstract}

Key words: moral reasoning, social perspective, moral decision making, relationship Psychology - Philosophy. 


\section{Introducció}

L. Kohlberg va ser un dels psicòlegs que més va aprofundir en el raonament $i$ en els posicionaments subjectius que es despleguen enfront d'una presa de decisió moral. En la seua explicació del desenvolupament moral, recupera les bases de la Psicologia genètica piagetiana i de la Filosofia moral kantiana. No obstant això, hi ha dos autors més als quals Kohlberg recorrerà per caracteritzar els processos implicats en la construcció del judici moral, sobretot aquell que es desplega en l'últim nivell del desenvolupament: G. H. Mead i J. Habermas. Particularment, amb aquest últim Kohlberg va mantenir un actiu i interessant diàleg sobre aspectes centrals de la seua teoria durant els anys previs a la seuamort. Identificar les articulacions en el pensament d'aquests tres autors contribueix, sens dubte, a afavorir una millor comprensió del procés de presa de decisions morals.

Habermas s'interessa per la teoria de Kohlberg a partir de la reconstrucció del materialisme històric. Des d'aleshores ha formulat importants contribucions per a la revisió crítica d'aquesta teoria que han servit particularment per a fonamentar-la. Pensem també que la teoria kohlbergiana ha impactat d'alguna manera sobre el pensament de Habermas i li ha permès aclarir i concretar alguns conceptes de la seua Filosofia moral. Entre aquests autors, el debat s'ha centrat en almenys quatre punts: la forma en què les recerques kohlbergianes s'han nodrit de l'enfocament hermenèutic proposat per Habermas per a les ciències socials; la relació entre la Filosofia i la Psicologia moral: la correcció plantejada per Habermas que porta Kohlberg a abandonar la hipòtesi de la identitat, a adoptar la hipòtesi de la complementarietat i a revisar el postulat de la jerarquia dels estadis; la vinculació entre el desenvolupament moral i el desenvolupament de la competència comunicativa; la reinterpretació habermasiana de l'estadi 6 .

Aquest article té per objectiu reprendre els dos últims eixos del debat Kohlberg-Habermas esmentats. I, així mateix, rescatar la manera en què, tant Kohlberg com Habermas, han recorregut al pensament de Mead per sostenir conceptes fonamentals de la seua teoria, posant en evidència la interrelació d'aquests tres sistemes teòrics. Habermas s'ocuparà de mostrar que la proposta de G. H. Mead permet resoldre els problemes en què cauen els científics socials a l'hora d'intentar explicar els processos d'individualització, substituint aquest terme pel d'individuació. Aquesta noció dóna compte d'un procés lingüísticament mediat de socialització i simultàniament de constitució d'una biografia conscient de si mateixa. D'altra banda, Kohlberg prendrà l'interaccionisme social de Mead per explicar el desenvolupament de la perspectiva social i l'enfocament del cognitivisme social. 


\section{La presa de decisions en la teoria del desenvolupament moral}

A mitjan segle passat, l'aparició de la teoria kohlbergiana revolucionà les recerques i conceptualitzacions sobre el desenvolupament. Fins aleshores, el principal interès dels investigadors havia estat usar verbalitzacions per a predir conductes, com ara la delinqüència juvenil, o faltes més freqüents a la moral, com ara copiar a classe. Molts dels intents d'avaluació dels valors morals s'havien enfocat en la conducta observable a partir de la qual eren inferits els valors sustentats pels infants. D'aquesta manera, els investigadors, en l'esforç per registrar la conducta, van prestar escassa atenció a la conceptualització dels valors morals i als mètodes apropiats per a mesurar-la, tot i que tant la literatura com les experiències de recerca destacaven la complexitat de les relacions entre els valors i la conducta moral. Els models que havien simplificat aquesta relació van conduir a prediccions fallides, a un rebuig consequient per les tècniques de mesura i a una proliferació d'instruments de verificació, aparentment amb l'esperança que alguna cosa pogués predir la conducta moral (Rest, 1979: 4).

En contrast amb aquesta orientació, l'any 1938 Piaget publica els resultats d'un estudi que té el propòsit d'explicar per què i com un subjecte valora certes coses des del seu propi punt de vista, considerant les verbalitzacions en funció del seu interès per revelar el món interior del subjecte. Piaget va entrevistar una gran quantitat d'infants en relació amb diverses situacions morals. A partir d'aquest estudi va poder comprovar que els infants entrevistats posseïen intuïcions sobre el que és correcte o incorrecte des del punt de vista moral, i que aquestes eren dràsticament diferents a la que tenien els adults. Aquest descobriment el va portar a postular les diferents organitzacions cognitives subjacents al pensament infantil, cada una amb la seua lògica i la seua manera d'interpretar l'experiència particular.

Les conclusions de Piaget (1984) respecte a la naturalesa i el funcionament de la moralitat infantil provenen de dos tipus d'experiències clíniques. La primera és l'observació de grups d'infant jugant a boletes i la segona és una entrevista personal amb infants ginebrins de diferents classes socials, als quals Piaget relata contes o «histories parelles» que exigeixen als infants la producció de judicis morals basats en la informació donada. En aquestes segones experiències, Piaget centra la seua atenció en l'anàlisi del judici moral, impressionat per la complexitat de les operacions mentals involucrades a descobrir el sentit de les experiències, les construccions cognitives necessàries per a assolir el més bàsic enteniment del món. A partir d'ací considera que el treball del psicòleg consisteix, doncs, a capturar la lògica i els patrons d'aquestes intuïcions postulant les estructures cognitives subjacents.

Rest (1979: 5) resumeix els principals assoliments de Piaget en: (1) la definició de l'àrea problemàtica i la construcció teòrica del judici moral; (2) la 
introducció de mètodes per a l'estudi del judici moral; (3) la identificació de dotzenes d'indicadors específics del pensament moral infantil a partir dels quals es pot inferir l'estructura cognitiva subjacent; i (4) l'aportació de dades empíriques en què recolzar la seua teoria. No obstant aquests assoliments, per a Rest, Piaget no va aconseguir desenvolupar un programa de recerca complet per a l'estudi de la moralitat que anara més enllà d'una caracterització, limitada en última instància, de les estructures cognitives subjacents a les verbalitzacions i de com aquestes estructures canvien amb el temps.

L'obra de Piaget va desencadenar altres estudis que s'adherien al seu pensament o intentaven refutar-lo (Kay, 1976), encara que no van sorgir treballs molt significatius que continuaren amb aquesta línia. Kohlberg reprèn el treball de Piaget i contribueix a acabar d'elaborar la perspectiva evolutiva cognitiva, expandir el programa de recerca i aplicar les idees a l'educació. James Rest (1979: 7) destaca que les recerques sobre el judici moral a partir de Kohlberg, es van enriquir teòricament, es van tornar molt consistents gràcies als descobriments diverses vegades verificats i interconnectats, i van desenvolupar el seu potencial d'utilitat social.

L'objectiu primari de Kohlberg era estendre a l'adolescència les recerques sobre el desenvolupament del judici moral en l'infant de Piaget. Centrant-se en l'estudi del judici moral va considerar, igual que Piaget, que l'infant és un filòsof moral, és a dir, posseeix construccions morals actives, que estructura els seus propis significats entorn de categories universals. Els estudiants entrevistats per Kohlberg (1983), malgrat intentar, primerament, conformar els seus interlocutors donant el que es considera «la resposta correcta», després proporcionaven raons allunyades de les expectatives de la cultura adulta, raons que provenien de la seua pròpia lògica interna i clara, construccions cognitives qualitativament úniques que constituïen una seqüència o ordre invariant. Amb aquests descobriments, Kohlberg va formular una teoria dels estadis morals que completa i reestructura els tres estadis descrits per Piaget.

Amb això s'inaugura una nova fase en les recerques del desenvolupament moral, on els esforços de la comunitat científica enrolada en el paradigma del desenvolupament moral social-cognitiu se centraran en la construcció d'un mètode, d'un instrument de mesura vàlid i confiable. La construcció i aplicació de diferents mètodes d'avaluació del desenvolupament moral va possibilitar integrar una nombrosa base de dades que proporcionà un sòlid suport al paradigma del desenvolupament moral cognitivista, i li va permetre resistir i superar amb èxit les nombroses crítiques i objeccions que es van fer entorn dels punts més controvertits de la teoria, com el seu formalisme, la continuïtat o discontinuïtat judici-acció, etc. 


\section{L'enfocament evolutiu-cognitiu i la perspectiva estructuralista del raona- ment moral}

Els estudis de Kohlberg i els investigadors del desenvolupament moral han anat completant i perfeccionant l'enfocament per a abordar la moralitat iniciat per Piaget: la perspectiva evolutiva-cognitiva. A més, Kohlberg (1984: 238) s'adhereix als criteris utilitzats per Piaget per diferenciar la seua concepció dels estadis d'altres models alternatius dins de la Psicologia evolutiva. La concepció estructuralista de Piaget marca la distinció fonamental. Per a Piaget, una estructura és un sistema de lleis de transformació que organitza i governa les operacions de raonament. Aquest sistema formal de govern es reflecteix o manifesta en les respostes reals de l'individu davant conflictes o problemes, la qual cosa condueix necessàriament a distingir, d'una banda, entre forma i contingut, i de l'altra, entre competència i performance, a l'hora de sostenir una determinada metodologia que permeta identificar les estructures.

Per a Kohlberg, el contingut dels judicis morals és relatiu a la cultura i al desenvolupament moral, però darrere d'opcions de valors i normes diferents, pot estar operant una mateixa estructura. És a dir, pot haver-hi diferents subjectes que, condicionats per factors socioculturals particulars, oferisquen davant un mateix problema respostes diferents i, en canvi, coincidisquen en els criteris d'orientació última - estructura- que fonamenten les seues respostes. De la mateixa manera es pot donar el cas que dues persones amb estructures de judici diferents trien el mateix valor, sense que això signifique que tinguen la mateixa perspectiva moral.

D'altra banda, encara que les estructures morals es modifiquen a mesura que evolucionen, aquestes conserven certes característiques o tendències invariants. En conseqüència, independentment de la multiplicitat de continguts valoratius que puguen entrar en joc en cada decisió, la forma i no el contingut és el que atorga regularitat i estabilitat en el judici moral. El subjecte sempre justificarà els judicis i accions, propis i aliens, a partir de la perspectiva de la seua estructura.

D'aquesta manera, en un enfocament diacrònic és possible advertir que els avanços en el desenvolupament que impliquen el pas d'un estadi a un altre suposen alhora una reorganització conceptual i lògica i un aprofundiment de funcions invariantsque es troben des del primer fins a l'últim estadi moral.

Des d'aquesta perspectiva estructuralista, el procés de presa de decisions és un moment clau en el desenvolupament. En primer lloc, perquè la presa de decisions es desencadena a partir d'un estímul, una interpel·lació al subjecte que posa en acció les estructures lògiques-cognitives i morals. Si el subjecte disposa de prou elements per a respondre a aquest desafiament, si més no, la necessitat 
de prendre una decisió desencadena processos de reordenament i fiançament de certes funcions. Si les estructures del subjecte no poden respondre al desafiament, aquest generarà un desequilibri que és el motor del desenvolupament.

Tal com ho ha explicat Piaget, quan les estructures es mobilitzen entren en joc dues funcions invariants o operacions bàsiques. El subjecte construeix la seua estructura mitjançant una diferenciació i integració cognitiva de nous elements, per això a mesura que s'avança en el desenvolupament es reconeixen en la cognició un major nombre d'elements o variables, als quals s'assimila a les estructures preexistents amb un major grau de precisió i compatibilitat. Per a Kohlberg (1984: 222) en el pla moral, el criteri psicològic es complementa amb l'ètic-filosòfic de prescriptivitat i universalitat. La prescriptivitat implica una diferenciació creixent entre el que és moral i no moral. Al seu torn, la universalitat porta a una més completa realització del que és moral. Tots dos criteris defineixen la manera com l'estructura o l'estadi nou transforma l'anterior per assolir un equilibri més estable i ampli. A partir d'aquesta concepció de l'adequació moral dels estadis superiors es pot establir i justificar l'estadi 6 com l'etapa final del desenvolupament, encara que aquest no siga un estadi empíricament i naturalment verificable. La postulació i descripció del raonament moral propi de l'estadi 6 opera com un model analític per a comprendre els processos que es desencadenen a l'hora de prendre una decisió moral.

Segons Kohlberg, a mesura que el subjecte va avançant en el seu desenvolupament, la presa de decisions morals es torna un procés més complex que permet posicionaments més consistents en termes psicològics i morals. Per explicar què passa en el pla psicològic, Kohlberg recupera la teoria de l'adopció de rols, o, com ell l'anomena, musical chairs. Per definir els components normatius presents en la presa de decisions morals, Kohlberg recorre a la perspectiva kantiana i neokantiana; en aquest marc els diàlegs que entaula amb Habermas, i les reinterpretacions d'aquest últim sobre aspectes centrals de la teoria del desenvolupament moral, són de gran rellevància.

\section{El desenvolupament de la perspectiva social: base psicològica del procés de presa de decisions morals}

Sabem que per a Kohlberg hi ha dos factors condicionants del desenvolupament moral: les estructures lògic-cognitives i els estímuls del medi social. La perspectiva interaccionista heretada de Piaget és refermada i potenciada per l'articulació amb la teoria de G. H. Mead. L'interaccionisme simbòlic en què s'inscriu el pensament de Mead observa com es configura la societat a partir dels individus que interactuen a través de símbols i significats aprehesos en el procés de socialització i configuració del pensament humà. 
Diu Tomasini (2010) que es reconeix Mead com un dels primers autors a esforçar-se per formular una teoria de la persona com a emergent d'una matriu de relacions intersubjectives i de proposar la comunicació simbòlica com a mecanisme per a la seua emergència. D'ací la seua importància per a comprendre els processos de construcció de la subjectivitat moral.

\section{$\mathrm{El} \ll \mathrm{mi} » \mathrm{i}$ el «jo» en la constitució de la persona}

Per a Mead, l'esquema de constitució de la persona està ancorat en el procés simbòlic, en la mesura en què els símbols i signes estructuren disposicions comportamentals. L'infant pot conferir sentit als seus comportaments a partir de les interpretacions que rep dels altres, quan aquests reaccionen als seus actes. D'aquesta manera va incorporant al camp de la seua experiència les actituds socials -al principi particulars, lligada als altres significatius- que progressivament es generalitzen fins a incorporar les actituds organitzades del grup social, que és el que introdueix organització en la persona (Tomasini, 2010: 139).

El que constitueix una persona és el procés social d'influir sobre altres en un acte social i després adoptar l'actitud dels altres que ha estat provocada per l'estímul, i per fi reaccionar al seu torn enfront d'aquesta reacció (Mead, 1982: 199).

Aquesta idea de reflexivitat que va ser presa tant per Kohlberg com per Habermas suposa un desplaçament molt important de les diferents posicions del determinisme social. Mitjançant la participació en els intercanvis socials l'individu es converteix en un objecte per a si mateix, perquè es descobreix anticipant les actituds dels altres que estan implicats en la seua acció i ajustant la seua resposta d'acord amb això. És a dir, un anticipa el que l'altre faria en resposta a un mateix i ajusta la seua pròpia acció; al seu torn l'altre fa el mateix. Aquesta etapa d'internalització de les actituds dels altres particulars suposa un procés progressiu d'ampliació segons el qual l'infant comença anticipant les reaccions conductuals de l'altre concret fins a arribar a anticipar, no ja els comportaments, sinó les expectatives comportamentals de l'altre.

Tenim aleshores un «altre» que és una organització de les actituds dels que estan involucrats en el mateix procés. La comunitat o grup social organitzat que proporciona a l'individu la seua unitat de persona poden ser anomenats «l'altre generalitzat» (Mead, 1982: 184-185).

L'actitud de l'altre generalitzat és l'actitud de tota la comunitat en aquesta forma que la comunitat exerceix el seu control sobre el comportament dels membres individuals; perquè d'aquesta manera el procés o comunitat social 
entra, com a factor determinant, en el pensament de l'individu. La instauració de l'altre generalitzat, en la mesura que representa una organització definida de la comunitat -la sèrie d'actituds organitzades dels altres-, inclou un factor de determinació en la persona. És la fase que Mead ha anomenat el «mi»:

... en la mesura en què l'individu desperta en si les actituds dels altres, sorgeix un grup de reaccions organitzades. I el fet que aconseguisca tenir consciència de si és degut a la capacitat de l'individu per a adoptar les actituds d'aquests altres en la mesura en què aquests poden ser organitzats. L'adopció de totes aquestes sèries d'actituds organitzades li proporcionen el seu «mi»; aquesta és la persona de la qual té consciència (Mead, 1982: 203).

Com assenyala Tomasini $(2010,149)$, el «mi» és una instància que representa la possibilitat d'adopció d'expectatives de comportament diverses. En la formació del self l'individu arriba a pensar-se a si mateix i a conferir sentit als seus actes a partir de les perspectives particulars d'altres membres del mateix grup social, així com des de la perspectiva generalitzada d'una comunitat social. Aquestes apareixen en un curs d'acció, davant les situacions problemàtiques que l'individu afronta i l'obliguen a considerar pluralitat de punts de vistes. Això permet comprendre la socialització a partir d'experiències inscrites en una pluralitat de perspectives.

Hi ha ací una idea de totalitat -l'altre generalitzat- que opera com a context de significació de les accions individuals. Però el plantejament no s'esgota ací. Ja Mead diferencia el «jo» del «mi» d'un actor, i amb això introdueix la contingència en l'acció. El «jo» és en Mead una fase del self que refereix a un principi de l'acció, com a reacció a les actituds dels altres que permet la novetat en la situació.

L'individu reacciona constantment a aquesta comunitat organitzada, expressant-se a si mateix (...) el fet que hagen d'actuar de certa manera comuna, no els priva d'originalitat. El llenguatge comú existeix, però se'n fa un diferent ús en cada nou contacte entre persones; l'element de novetat de la reconstrucció es dóna gràcies a la reacció dels individus envers el grup a què pertany (Mead, 1982: 222-223).

Mead afirma que el «jo» i el «mi» són essencials per a la plena expressió de la persona i el predomini d'un o de l'altre depèn de la situació, ja que els concep en relació amb l'acció en curs. Cal adoptar l'actitud dels altres d'un grup a fi de pertànyer a la comunitat, però la reacció constant a les actituds socials canvia en aquest procés a la comunitat mateixa a la qual es pertany, encara que aquests canvis siguen petits i trivials.

La persona és essencialment un procés social que es du a terme, amb aquestes dues fases distingibles. Si no tinguera aquestes dues fases, no 
podria existir la responsabilitat conscient, i no hi hauria res de nou en l'experiència (Mead, 1982: 205).

Tal com Habermas (1990: 216) ho explicarà després, les relacions entre el «mi» i el «jo» es tradueixen en l'autodeterminació i autonomia del subjecte en el marc de relacions de reconeixement. La instància del «jo», que es constitueix sobre el «mi», apunta a representar l'elevació del si mateix per sobre de l'individu institucionalitzat. Per més regit per normes que estiga el comportament, a ningú se li pot llevar la iniciativa, la qual cosa significa, senzillament, poder iniciar una cosa nova.

Des de la perspectiva de Tomasini (2010: 150 i 151), hi ha almenys tres raons rellevants per a reconsiderar les categories de Mead com un model psicosocial que permet integrar diferents dimensions de la socialització com a procés de subjectivació. En primer lloc, per la idea del fòrum social que serveix com a escenari de constitució del self. Des d'aquest model, proposa que l'atribució de sentit als nostres actes es realitza sempre en diàleg amb -o contra- les perspectives dels altres. En segon lloc, perquè l'intercanvi de punts de vista inclou la perspectiva de l'altre concret i de l'altre generalitzat. D'aquesta manera, en els nostres judicis, decisions o alternatives d'acció disposem tant de la perspectiva d'un grup particular com d'una comunitat o grup social organitzat com un tot, que opera com a marc més ampli de referència des del qual jutjar les conseqüències possibles de les nostres accions no solament per als altres pròxims, amb els quals tenim lligams vinculants, sinó també per als altres anònims que pertanyen a una comunitat social ampliada. I, en tercer lloc, perquè la definició del «jo» com a principi organitzador de l'acció evita reduir l'individu a un reflex de les definicions i expectatives dels altres. És molt interessant la consideració que fa Tomasini (2010: 151) sobre la intersubjectivitat com un espai intersticial en què són claus les interpretacions dels «altres» que ofereixen un horitzó de sentit en el qual poden ancorar les motivacions per al propi comportament. Però, alhora, en aquest espai es visualitza l'emergència d'esdeveniments que no s'ajusten al que s'espera o que, tot i alinear-se amb el que s'espera, produeixen algun desplaçament.

\section{L'adopció ideal de rols i l'altre generalitzat com a fites del desenvolupa- ment moral}

Kohlberg ha recuperat i actualitzat les aportacions de Mead com a nucli dur de la seua concepció sobre l'evolució del pensament moral. El sorgiment de la perspectiva social, o de l'altre generalitzat i l'adopció ideal de rols són les fites més importants del desenvolupament moral. 
El procediment anomenat per Kohlberg musical chairs -reversible roletaking-suposa que subjectes en un procés d'interacció simbòlicament mediat poden adoptar el punt de vista de qualsevol dels participants. Aquesta competència és pròpia del nivell superior del desenvolupament i dóna compte d'estructures totalment consistents i reflexives. En principi, un es pot posar en el lloc de qui està més pròxim, les persones del nostre cercle d'amistats, en els processos de socialització primària. Però la construcció de la perspectiva de l'altre generalitzat requereix l'ampliació dels punts de vista per abastar aquells que fins i tot estan distants de la meua posició vital i incloure el d'altres que participen com a implicats virtuals.

La perspectiva de la tercera persona, com l'anomena Kohlberg, de l'altre generalitzat, o l'operació de reversibilitat, de la qual s'ocupa Habermas com veurem més endavant, constitueix la fita més important en el desenvolupament moral. Només des d'aquesta perspectiva el subjecte pot construir la noció de normes universalitzables que afirmen una concepció àmplia de la justícia.

No obstant això, la idea d'assumpció ideal de rols no és solament un procediment, una operació de justícia per a resoldre un dilema moral, sinó també una condició per a advertir-lo i per a experimentar-lo com a tal.

... en l'estadi 6 es passa pel següent procés d' 'ideal role taking':

- imaginar-se en la posició de cada persona en la situació concreta i considerar totes les reclamacions que cadascú podria fer -o que un podria fer en la seua posició-.

- després, imaginar que un no sap quina persona és en la situació, ${ }^{1}$ i a preguntar-se quines coses hauria de reclamar i a quines coses hauria de renunciar; i, finalment, formular un judici moral conseqüent amb les reclamacions ... reversibles -aquelles que un secundaria no sabent quina persona era en la situació concreta- (Mifsud, 1983: 68).

Aquest model d'adopció ideal de rols, que Kohlberg assimila Mead, proporciona clars indicadors de com s'operaria en una situació de presa de decisions morals en l'últim estadi del desenvolupament moral.

Tanmateix, per a Habermas (1991a), aquest model seria limitat ja que s'esgotaria en l'esfera del monològic, és a dir, en un examen de consciència individual, quan les condicions normatives del discurs exigeixen un tipus de racionalitat dialògica, una transició -com s'ha dit- del jo al nosaltres. Per això, Habermas reinterpreta i amplia la concepció de l'adopció ideal de rols, introduint el discurs pràctic com a procediment que garantisca la validesa dels judi-

1. Ací s'introdueix la teoria del «vel de la ignorància» de Rawls per a l'anomenada situació originària. 
cis normatius construïts en l'estadi 6. Entenent que una de les preocupacions fonamentals del pensament post-convencional és l'argumentació normativa, això és, la possibilitat de justificar les decisions en funció de principis ètics, el discurs moral argumentatiu s'ha de concebre, doncs,

... com un procés orientat a l'enteniment -intersubjectiu- que ... exigeix al mateix temps a tots els participants una adopció ideal de rols. La idea del discurs transforma l'adopció ideal de rols, anticipada per Kohlberg primàriament com un procediment individual i privat, en un acte públic la idea del qual exigeix que siga posat en pràctica per tots en comú (Habermas, 1991a: 186).

Però la necessitat d'una comunitat de verificació i fonamentació de l'ètica discursiva de Habermas sorgeix també com un mecanisme psicològic d'adaptació funcional a la societat, bàsic per al sorgiment de la consciència moral. Per a Mead, aquest és un mecanisme autoreflex, on la

... capacitat per a adoptar les actituds socials d'altres individus i també les de l'altre generalitzat cap a ell, dins de la societat organitzada de què és membre, possibilita que s'incorpore a si mateix com un tot objectiu, dins de la seua pròpia esfera experimental, i així, pot integrar i unificar conscientment els diferents aspectes de la seua persona per a formar una sola personalitat conscient, coherent i organitzada... (Mead 1982: 320).

La concepció de l'adopció ideal de rols suggereix que, només en el grau en què un pot adoptar el paper de l'altre, es pot mirar a si mateix i reaccionar davant seu-consciència reflexiva-. Des del punt de vista moral, la reconstrucció individual, reflectida en una reorganització social, ens planteja una exigència fonamental: que tots els interessos involucrats siguen tinguts en compte; aquesta és l'única prova per a establir la correcció dels nostres actes.

Diu Mead (1982: 388) que els judicis morals que es dirimeixen en la presa de decisions es resolen a partir de l'elaboració d'una hipòtesi social, ningú pot fer-ho simplement des del seu punt de vista. En això es basa la seua teoria de la «universalitat social» que entén que, així com allò que un individu fa o diu ha de ser comprensible o cert per als altres involucrats en una activitat comuna, l'acte moralment correcte és aquell que ha estat assentit per tots els involucrats. És a dir, la hipòtesi social ha de ser construïda mitjançant la comunicació i no com un mer experiment mental.

La instància del discurs argumentatiu és fonamental i decisiva, sorgeix com a condició necessària per a l'afirmació de la reflexió introspectiva. Si ens quedàrem en aquesta última, no faríem més que pressuposar la validesa intersubjectiva dels nostres judicis. La instància argumentativa la comprova en la praxi.

Si bé un subjecte racional i autònom pot, com assenyalava Mead, elaborar una hipòtesi social o universal mitjançant l'adopció de la perspectiva de tots els 
possibles afectats, si aquesta assumpció ideal de rols no és concebuda com a exigència normativa del mateix joc dialògic, només es tracta d'un exercici de comprensió intuïtiva personal. Per a Habermas, el discurs converteix les condicions inicials d'empatia comprensiva i la identificació amb l'altre en un procés cognitivosocial que es manifesta, d'una banda, en la comprensió de les pretensions dels altres, que resulten dels seus interessos particulars; i de l'altra, en la consciència de pertinença de tots els afectats, objectivament fonamentada a través de la socialització. En aquest nivell d'abstracció s'ha de separar tant la sensibilitat per a les pretensions individuals que provenen dels vincles i identitats accidentals, com el sentiment de solidaritat envers aquests vincles socials o de grup.

Si es té en compte ... que el fi d'aquest procés comprensiu d'enteniment, a saber, l'acord no forçat, solament es pot aconseguir pel vehicle de les bones raons, es posa en relleu amb més nitidesa que en Mead el caràcter reflexiu d'aquell discurs universal: no es pot imaginar solament com una xarxa d'interacció comunicativa, comprensiva de tots els potencials afectats, sinó com a forma reflexiva de l'acció comunicativa, és a dir, precisament com a argumentació (Habermas, 1991a: 188).

\section{La reconstrucció racional de l'estadi 6 (Kohlberg - Habermas) com a punt final del desenvolupament. El model de presa de decisions morals}

L'adopció ideal de rols com a procediment superlatiu i fonamental per a la presa de decisions morals requereix, com va postular Habermas, que les condicions normatives del discurs pràctic siguen garantides. Per això, l'ètica discursiva assumeix una relació de complementarietat i cooperació amb una teoria de la moralitat o del desenvolupament moral que identifique, per a la seua posterior promoció, les competències psicològiques fonamentals per a la realització empírica del diàleg.

En aquest sentit, tant Habermas com Apel reconeixen la teoria del desenvolupament moral cognitiu de L. Kohlberg com un recurs de confirmació de l'adequació operativa de l'ètica del discurs enfront d'altres filosofies morals, en postular el nivell post-convencional de la tipologia kohlbergiana com a etapa final del desenvolupament moral on la idea del discurs pràctic adquireix sentit i funcionalitat. Precisament, en el pensament post-convencional s'activen i expandeixen totes les operacions logicocognitives i morals sense les quals els procediments discursius no serien possibles, com ser

... la reversibilitat completa dels punts de vista, la universalitat en el sentit d'una inclusió de tots els afectats, i finalment la reciprocitat del reconeixement igual de les pretensions de cada participant per part dels altres (Habermas, 1984: 144). 
Podem esmentar tres aspectes que, per a Kohlberg, permeten caracteritzar l'últim nivell del desenvolupament moral: les operacions de justícia, el descentrament i el punt de vista moral.

\section{L'orientació deontològica i les operacions de justícia}

És en l'últim nivell del pensament moral -particularment l'estadi 6- anomenat per Kohlberg «post-convencional, autònom o de principis - principled-» on les operacions racionals bàsiques de la justícia assoleixen la més plena expressió a causa de l'orientació deontològica que hi adquireixen. En aquest nivell es percep un clar esforç per descobrir i definir valors i principis que tinguen validesa i aplicació general per sobre de l'autoritat del grup o de les persones que els sostinguen i per sobre de la mateixa identificació d'un amb aquest grup. La presa de decisions morals es resol amb més validesa i consistència perquè el principi de justícia és assumit en aquesta etapa com la màxima orientació del criteri moral.

Per a Kohlberg (1984: 623) són operacions de justícia la igualtat, l'equitat, la reciprocitat, la universalitzabilitat i l'adopció ideal de rols. Aquestes operacions són complementàries entre si, i ja és possible rastrejar-les, en incipients indicis, en etapes anteriors del desenvolupament moral. Només en el nivell post-convencional assoleixen l'expressió més completa.

En l'estadi 6, el sentit de la justícia es concep en termes dels drets de la humanitat independentment de la societat civil, $i$ aquests drets es fonamenten en el respecte envers la dignitat de cada home com a fi en si mateix. Per això, aquest estadi es defineix per un concepte universal de justícia. Això és, en una situació de conflicte, i de presa de decisió moral, la solució justa és aquella que pot ser acceptada per tots, considerant a tots com a lliures i iguals (Mifsud, 1983: 82).

Del que s'ha dit anteriorment es dedueix que, per a l'ètica deontològica, la validesa dels principis morals es garanteix a partir del procediment formal que s'empra per a la fonamentació racional d'aquests principis, la qual cosa determina la seua possibilitat de generalització o universalització. En l'estadi 6, l'operació prescriptiva de l'adopció ideal de rols adquireix el caràcter procedimental.

Sobre el plantejament deontològic d'inspiració kantiana de Kohlberg, s'han fet nombroses crítiques. Potser la que tingué més ressò va ser la de Carol Gilligan (1994), que objecta el biaix masclista i euroccidental de la teoria kohlbergiana, perquè assumeix com a orientació moral última la de la justícia. No ens posarem en aquestes crítiques, ja que excedeixen el nostre interès, però sí assenyalarem que, enfront d'aquestes, Kohlberg sosté que la teoria del desenvolupament moral no ha fallat a demostrar que, en l'últim nivell evolutiu del 
raonament moral, la preocupació fonamental s'orienta cap a la cerca de la justícia, com a màxim principi ètic, on se sustentarien tots els altres principis com a subsidiaris. La solidaritat, la responsabilitat i la cura de l'altre serien ingredients del concepte de justícia amplificat i aprofundit de l'estadi 6.

En la seua resposta als reclams de Gilligan, Kolhberg (1984: 340) admet la necessitat d'ampliar el domini moral, fins ara restringit als raonaments sobre qüestions de justícia, mitjançant la consideració de la preocupació per la cura i la responsabilitat majorment viscuda en les relacions d'obligacions especials amb la família i els amics. "Així introdueix un principi complementari al de justícia, que des del seu punt de vista seria el 'principi de benevolència' com a corresponsabilitat pel bé de l'altre...» (De Zan, 1991: 181).

Sobre aquest intent de respondre a les crítiques, Habermas (1991a) reconeix que la intencionalitat de Kohlberg és correcta, però la tradueix en conceptes equivocats ja que atribueix al principi del respecte igualitari per tota persona un significat expandit, que comprèn tant el tracte igualitari com la benevolència. Aquesta nova perspectiva de Kohlberg encara conserva per a Habermas un cert biaix individualista, perquè no reflecteix clarament l'estreta connexió de la preocupació pel bé del proïsme amb l'interès pel bé comú. Per tant, el principi complementari del de la justícia

... no és la benevolència, sinó la solidaritat. Aquest principi té la seua arrel en l'experiència que cadascú ha de fer-se responsable de l'altre, perquè tots han d'estar igualment interessats en la integritat del context vital comú del qual són membres. La justícia concebuda deontològicament exigeix, com la seua altra cara, la solidaritat. No es tracta en aquest cas de dos moments que es complementen, sinó més aviat de dos aspectes de la mateixa cosa. Tota moral autònoma ha de resoldre al mateix temps dues tasques: en reivindicar un tracte igual, i amb això un respecte equivalent per la dignitat de cadascun, fa valer la inviolabilitat dels individus en la societat; i com a membres d'una comunitat en què s'han socialitzat, protegeix les relacions intersubjectives de reconeixement recíproc... Les normes morals no poden protegir l'un sense l'altre, és a dir: no poden protegir la igualtat de drets i les llibertats dels individus sense el bé del proïsme i de la comunitat a la qual aquests pertanyen (Habermas, 1991a: 197 i $1991 b$ : 107 i 108).

\section{Descentrament de la perspectiva social, reflexivitat ètica i superació del relativisme contextual etnocèntric}

El nou principi complementari al de la justícia es vincula amb el fet que l'ampliació de la perspectiva que s'opera amb el pas del nivell convencional al post-convencional, canvia les relacions cognitives del social al moral. És a dir, 
de la comprensió del món social i de les interaccions orientades per les normes que regeixen el social, a un intent de comprovació de la validesa d'aquestes normes. En el nivell dels principis, el subjecte es col·loca en el pla ètic o metamoral, en el sentit de poder analitzar críticament els judicis morals i les seues conseqüències en l'acció.

Kohlberg (1984: 242) destaca que Piaget reconeix l'existència d'una abstracció reflexiva que acompanya el moviment d'un estadi a un altre. Aquesta reflexió és més aviat un procés estructural inconscient d'organització de sistema operatius, on les operacions són formes interioritzades d'acció. En un sentit empíric això implica que els estadis cognitius i morals es relacionen amb l'acció en forma directa. És possible concebre, en aquest sentit, que en l'últim nivell de desenvolupament aquests esquemes formals d'operació afavorisquen dues competències: d'una banda, una reflexió sobre les orientacions filosòfiques alternatives representatives de cada estadi o nivell de raonament moral; i de l'altra, un distanciament de la pràctica de la vida quotidiana a partir del qual el subjecte es va independitzant de les seues circumstàncies i es va colllocant en un pla que Habermas anomenameta-comunicatiu, des d'on comença a fer-se problemàtica la força normativa del fàctic en termes de la seua validesa.

El descentrament en el nivell post-convencional es manifesta, doncs, en la introducció d'un nou concepte de legitimitat de les normes d'acció que es divideix en dos elements:

... el fet que alguna cosa es reconega de facto i que alguna cosa siga digna de reconeixement; la vigència social de les normes en vigor ja no és coincident amb la validesa de les normes justificades. Aquestes distincions en els conceptes de norma i validesa de l'haver de ser es corresponen amb una distinció en el concepte de l'haver de ser: el respecte a la llei ja no compta com a motiu ètic per se (Habermas, 1984: 190).

D'aquesta manera Habermas està descrivint el sorgiment d'una de les competències fonamentals del pensament moral post-convencional la discriminació i concreció dels dos moments de construcció dels judicis morals: el de la justificació i el de l'aplicació.,

... atès que en el nivell convencional -moralitat interpersonal i moralitat del sistema social- no es posa en qüestió l'eticitat de les relacions familiars o intracomunitàries $i$, per tant, basta la simple 'narrativa' individual. Però en el nivell post-convencional resulta decisiu, per definició, posar en dubte la validesa social de l'axiologia comunitària mitjançant la construcció intersubjectiva de les regles vàlides ... així com el subsegüent procés d'aplicació de la regla general constructa $-\mathrm{o}$ justificada com a vàlida- als casos concrets en el seu context històric-cultural (Habermas, 1984: 130). 


\section{El «punt de vista moral»}

En l'etapa post-convencional, l'acció moral recolza en una presa de decisions basada en normes racionalment fundades, això és, una acció orientada per criteris morals. Si bé és cert que en els estadis anteriors ja apareix unida la intuïció del moral amb la idea d'una solució consensual, Habermas destaca que els participants parteixen d'idees de la vida bona que permeten ordenar de forma transitiva les necessitats del conflicte, però on els punts de vista que han de possibilitar el consens són controvertits.

Al marge de les contingències comunes de l'origen social, la filiació política, l'herència cultural, les formes tradicionals de vida, etc., els subjectes d'acció competents només es poden referir a un punt de vista moral, és a dir, a un punt de vista lliure de controvèrsies quan, tot $\mathrm{i}$ tenir orientacions axiològiques diferents, no poden sinó acceptar aquell (Habermas, 1984: 191).

En termes psicogenètics, els esquemes -formes interioritzades d'acció, ara descentrades-, es manifesten en formes prescriptives de roletaking en situacions morals concretes. Les operacions o competències constitueixen en el nivell post-convencional, però particularment en l'estadi 6 , sistemes raonaments totalment equilibrats i reversibles que permeten assumir coherentment i consistentment el «punt de vista moral».

Habermas mostra, des d'una perspectiva genealògica, que enfront de la presa de decisions moral i les resolucions de conflictes en condicions d'un discurs pràctic, els parlants competents que disposen de l'estructura de raonament moral pròpia de l'estadi 6, posen en joc el «punt de vista moral». Allí parteix de la diferenciació entre tres tipus de reflexió pràctica: la pragmàtica, l'ètica i la moral, entre les quals es plantejarien posicions epistèmiques inconciliables, que analitza genealògicament.

Per a Habermas (1999: 77 i 2000: 109 i ss.), en els discursos de fonamentació i aplicació conduïts amb èxit s'evidencia que les qüestions pràctiques es diferencien sota el rigorós punt de vista moral: les qüestions morals relatives a la convivència justa se separen, d'una banda, de les qüestions pragmàtiques relatives a l'elecció racional i, de l'altra, de les qüestions ètiques relatives a la vida bona o no fracassada.

Habermas considera que la racionalitat pragmàtica, la racionalitat ètica i la racionalitat moral es posen en joc en diferents instàncies de la formació discursiva de la voluntat. En un primer moment, la raó pragmàtica avalua les preferències i objectius des de la perspectiva d'una primera persona. Sobre aquestes «dades» decideix en última instància l'autoritat epistèmica de qui actua, que és qui ha de saber quines són les seues preferències i objectius. 
La racionalitat pràctica es mou ací en l'horitzó de la racionalitat teleològica i amb l'objectiu de trobar tècniques, estratègies o programes apropiats. Porta a recomanacions que en casos senzills tenen la forma semàntica d'imperatius condicionats (Habermas, 2000: 111).

Però tan aviat com els valors o finalitats mateixes es tornen problemàtics, la pregunta què haig de fer? remet més enllà de l'horitzó de la racionalitat estratègica. Es continua mantenint la perspectiva de la primera persona, però aquesta

... significa ací no la limitació egocèntrica a les meues preferències, sinó que assegura la referència a una història vital que es troba sempre ja incrustada en tradicions i formes de vida intersubjectivament compartida (Habermas, 1999: 56).

La pregunta qui sóc? i qui hauria de ser? s'obri aleshores més enllà del món subjectiu de l'actor, accessible privilegiadament per aquest, cap a un món social intersubjectivament compartit. Així, la reflexió sobre les experiències, pràctiques i formes de vida comunes porta a consciència un saber ètic sobre el qual ja no disposem, gràcies a l'autoritat epistèmica de la primera persona del plural. Per aquest motiu la reflexió pràctica que s'apropia críticament aquest saber intuïtiu requereix una perspectiva social. La racionalitat ètica tracta de les qüestions sobre com ens entenem com a membres d'una comunitat moral, sobre com hem d'orientar la nostra vida, del que és el millor per a nosaltres a llarg termini i vist en conjunt.

Desd'aquesta perspectiva, diu Habermas (2000: 114), les altres persones cobren significat en la mesura en què queden entrellaçades amb la meua identitat, amb la meua biografia i amb la meua particular constel-lació d'interessos. La formació del jo es produeix, com també els mostra Mead, en un context de tradicions que jo compartisc amb altres persones «... la meua identitat és també marcada i determinada per identitats collectives i la meua biografia es troba inserida en contextos de vida històrica que l'envolten».

Però les qüestions ètiques apunten en una direcció diferent que les morals: en les qüestions ètiques no és encara el tema la regulació de conflictes interpersonals d'acció que resulten d'interessos oposats. La racionalitat moral atorga prioritat absoluta del que és just enfront del que és bo, prioritat que expressaria el sentit de validesa categòric dels deures morals i no pot fonamentar-se mentre les obligacions es consideren únicament des del punt de vista ètic. Si la justícia és considerada solament com un element més integrat a la concepció del bé de cadascú, no hi ha cap motiu per a l'exigència que en cas de col-lisió de drets els deures només poden ser «superats» per deures i els drets per drets. Diu Habermas (1999: 59): «... La pregunta abstracta de què siga d'igual interès per a tots sobrepassa la pregunta ètica contextualitzada de què siga el millor per a nosaltres». 
Una llei és vàlida en sentit moral si pot ser acceptada per tots des de la perspectiva de cadascú. Atès que només les lleis universals compleixen la condició de regular una matèria en igual interès de tots, una persona accepta el punt de vista moral si com a legislador democràtic fa un examen sobre si la pràctica que resultaria del seguiment d'una norma hipotèticament ponderada poguera ser acceptada per tots els possibles interessats com a colegisladors potencials.

La voluntat s'ha alliberat de determinacions heterònomes tan sols quan, des del punt de vista moral, la seua compatibilitat ha estat examinada amb els interessos i orientacions de valor dels altres. ${ }^{2}$ Per això per a Habermas el punt de vista moral només pot sorgir i realitzar-se en condicions comunicatives que asseguren que tots examinen l'acceptabilitat de les normes elevades a pràctica universal també des de la perspectiva de les seues pròpies comprensions del jo i del món. La pràctica deliberativa és l'únic recurs possible per al punt de vista de judici imparcial sobre les qüestions morals.

\section{A manera de conclusió: dimensions del procés de presa de decisions morals segons Kohlberg, Mead i Habermas}

Els processos psicològics i ètic-normatius descrits donen compte de les operacions i procediments presents en una matriu modèlica de presa de decisions morals.

A partir de les aportacions d'aquests tres autors podem veure quins són els factors que hi estan involucrats, que, a efectes analítics, poden ser diferenciats però que en el terreny empíric operen alhora, de manera articulada i complementària. En la seua teoria de l'acció comunicativa, Habermas s'ha proposat l'empresa de derivar una hipòtesi de reconstrucció i fonamentació lògica-evolutiva de les etapes morals. Aquesta hipòtesi suposa que en la reconstrucció de les

2. «El desacoblament cognitiu» de la moral respecte de la vida bona té com a conseqüència la pèrdua d'una certa força motivacional. L'ètica discursiva reforça la separació entre judici i acció perquè considera que el punt de vista moral s'encarna en els discursos racionals. No hi ha cap transferència assegurada del judici obtingut discursivament a l'acció. Però per a Habermas també és cert que les bones raons compel·leixen a l'acció, per tant la feblesa de la voluntat deixaria entreveure la feble força de les raons epistèmiques. Aquesta concepció és convergent i s'enriqueix amb la de Kohlberg i Candee («The Relation of Moral Judgment to Moral Action». En Kurtines, W. i Gerwitz, J., Morality, Moral Behavior and Moral Development. N.J, John Wiley \& Sons, 1984) segons la qual la relació entre el judici i l'acció moral és unidireccional. Les estructures del judici influeixen sobre l'acció a través de dos tipus de judicis: els deòntics -judicis sobre el que s'hauria de fer o el que és correcte- $\mathrm{i}$ els de responsabilitat -judicis sobre el compromís per a executar una acció-. Deixem aquest punt de convergència per a un altre estudi. 
estructures social-cognitives del desenvolupament moral poden diferenciar-se tres dimensions d'anàlisi: l'adopció de la perspectiva social, el judici moral i les competències interactives.Des d'aquestes tres perspectives és possible comprendre de manera més complexa el procés de presa de decisions.

Per a Kohlberg, com hem assenyalat, el desenvolupament moral és un procés de reestructuració de les tendències humanes universals d'empatia -preocupació pel benestar dels altres- i de justícia -preocupació per la igualtat i la reciprocitat- en formes més adequades. En els dos primers nivells, aquestes tendències estan condicionades i segueixen una orientació heterònoma: el respecte a l'autoritat, el temor al càstig, l'aprovació social i l'adhesió a la norma. La presa de decisions morals es troba, doncs, igualment condicionada, però en el nivell post-convencional es torna conseqüència d'un pensament autònom i completament equilibrat.

En aquest punt, tant Kohlberg com Habermas recorren a la idea de Mead que les persones, com a subjectes capaços de llenguatge i d'acció, només queden individuades per via de socialització, per explicar com la transició cap al pensament moral autònom es dóna en el marc d'una comunitat de llenguatge i, per tant, en un món de la vida intersubjectivament compartit. En aquest procés de formació sorgeixen i es mantenen cooriginalment la identitat de l'individu i del col-lectiu a què aquest individu pertany. Com més progressa la individuació, més enredat es veu el subjecte individual en una xarxa cada vegada més densa i alhora més subtil de dependències recíproques i necessitats de protecció que corren el risc de no quedar satisfetes. La persona només desenvolupa, doncs, un centre interior en la mesura en què també s'estranya alhora en relacions interpersonals comunicativament establertes. Això explica els riscos i la vulnerabilitat crònica d'una identitat susceptible de sofrir menyscabament i crebant. Les morals estan tallades just a la mida d'aquesta necessitat de consideració i mirament. Doncs bé, com les morals tenen per finalitat compensar la vulnerabilitat d'éssers que queden individuats per socialització, de manera que mai no puguen afirmar la seua identitat per si mateixos, la integritat dels individus no es pot protegir sense protegir alhora la integritat del seu «món de la vida» comuna, que és el que fa possible les relacions interpersonals i les relacions de reconeixement recíproc. Aquest doble aspecte és el que Kohlberg tracta de fer ressaltar posant l'accent en les condicions intersubjectives del manteniment de la integritat de l'individu. Els mecanismes morals de protecció no poden assegurar la integritat de la persona individual sense assegurar al mateix temps i alhora la trama de relacions de reconeixement en què els individus, per estabilitzar la seua fràgil identitat, no poden estabilitzar-la sinó mútuament i estabilitzant alhora la identitat del seu grup.

Per això, a més dels esquemes lògics-cognitius, les experiències socials seran clau en aquests processos. Com més plurals i diversos siguen els contextos 
de socialització i les xarxes dels subjectes, majors actituds, rols i perspectives podran ser considerades en la presa de decisions. La qual cosa afavorirà la cooperació social, més enllà del simple control. Però, a més, això amplia decididament la capacitat d'adopció de l'altre generalitzat, la construcció de la hipòtesi social, que és una exigència psicològica, no solament formal, per a la presa de decisions.

Les motivacions i raons de la decisió racional, tant si és per aconseguir un fi com fer el bé o ser just,fonamentaran per a Habermas les alternatives d'acció i obriran o no les possibilitats, crearan les condicions per al discurs argumentatiu o constructor de normes morals.

En definitiva, la presa de decisions morals és un procés racional que es distingeix per un raonament centrat en les qüestions de justícia i benestar, per la reflexivitat i reversibilitat o intercanviabilitat de les perspectives assumides i pel punt de vista moral que porta a prescindir de les consideracions sobre les circumstàncies concretes, per poder examinar si la decisió presa pot tenir l'assentiment de tots els qui en són afectats.

\section{Referències}

De Zan, J. (1991). «Jurgen Habermas y Lawrence Kohlberg. Sobre la etapa superior de la evolución de la conciencia moral». En Cuadernos de Ética, 11/12 (juny/desembre).

Gilligan, C. (1994). La moral y la teoría. Psicología del desarrollo femenino. Mèxic, FCE.

Habermas, J. (1984). Conciencia moral y acción comunicativa. Barcelona, Península.

Habermas, J. (1990). Pensamiento post-metafísico. Madrid, Taurus.

Habermas, J. (1991a). «Justicia y Solidaridad. (Una toma de posición en la discusión sobre la etapa 6 de la teoría de la evolución del juicio moral de Kohlberg)». En Apel, K.-O.; Cortina, A.; De Zan, J. i Michelini, D. (eds.), Ética comunicativa y democracia. Barcelona, Crítica.

Habermas, J. (1991b). Escritos sobre moralidad y eticidad. Barcelona, Paidós. Habermas, J. (1999). La inclusión del otro. Barcelona, Paidós.

Habermas, J. (2000). Aclaraciones a la ética del discurso. Madrid, Trotta.

Kay, W. (1976). El desarrollo moral. Bs. As., El Ateneo.

Kohlberg, L. (1983). «El niño como filósofo moral». En Delval, J.: Lecturas de sicología del niño. Madrid, Alianza

Kohlberg, L. (1984). The Psychology of Moral Development. San Francisco, Harper \& Row.

Mead, G. H. (1982). Espíritu, persona y sociedad. Barcelona, Paidós. 
Mead, G. H. (1991). «La génesis del self y control social». En REIS, 55, pp. 165-186.

Mifsud, T. (S.J.). (1983). Los seis estadios del juicio moral: con aplicación pedagógica. Santillana, CIDE.

Piaget, J. (1984). El criterio moral en el niño. Barcelona, Martínez Roca.

Rest, J. (1979). Development in Judging Moral Issues. Minneapolis, University of Minnesota Press.

Tomasini, M. (2010). Un viejo pensador para resignificar una categoría psicosocial: George Mead y la socialización. En Athenea Digital, 17, març.

Data de recepció: $\quad 28-02-2017$

Data d'acceptació: 15-06-2017 